Поражение кожи при остром монобластном лейкозе (клиническое наблюдение)

Н.Г. Чернова, М. Н. Синицына, В. Н. Двирнык, А. М. Ковригина, Е. Е. Звонков, Е.Н. Паровичникова

ФГБУ «Гематологический научный центр» Минздрава России 125167 , г. Москва, Новый Зыковский проезд, д. 4

В настоящее время диагностика острых лейкозов не представляет особых трудностей и основывается на морфрологическом и иммуносренотипическом исследованиях костного мозга. Представлен нестандартный алгоритм верификации острого монобластного лейкоза у пожилой пациентки, протекающего с лейкемическим поражением кожи. Морфологическое и иммуногистохимическое исследования биоптатов кожи, лимфоузла и костного мозга позволили установить линейную принадлежность опухолевых клеток и своевременно верифрицировать диагноз лейкемии. Отсутствие комплексного клинического обследования в подобных случаях приводит к диагностическим ошибкам, поздней верисикации истинного диагноза и существенно ухудшает прогноз. Ключевые слова: острый монобластный лейкоз, экстрамедуллярные очаги поражения, лейкемическое поражение кожи.

Контактная информация: ngchernova@mail.ru. Вестник дерматологии и венерологии 2017; (1): 46—50.

\title{
Skin lesion at acute monoblastic leukemia (clinical observation)
}

N. G. CHernova, M. N. Sinicyna, V. N. Dvirnyk, A. M. Kovrigina, E. E. Zvonkov, E. N. Parovichnikova

Hematological Scientific Center

Novyj Zykovskij proezd, d. 4, Moscow, 125167, Russia

\begin{abstract}
At present diagnosis of acute leukemia does not represent any difficulties and is based on morphological and immunophenotypical bone marrow studies.

The paper presents a non-standard verification algorithm of acute monoblastic leukemia in elderly female patient, with leukemic skin lesion. Morphologic and immunohistochemical studies of biopsy materials of skin, lymph node and bone marrow allow establishing a linear membership of tumor cells and promptly verifying the diagnosis of leukemia. Lack of the overall clinical examination in such cases leads to diagnostic errors and to late verification of the true diagnosis and significantly worsens the prognosis.
\end{abstract}

Key words: acute monoblastic leukemia, extramedullar lesions, leukemic skin lesion.

Corresponding author: ngchernova@mail.ru. Vestnik Dermatologii i Venerologii 2017; 1: 46—50. 
В настоящее время диагностика острых лейкозов не представляет особых трудностей и основывается на морфологическом и иммунофенотипическом исследованиях пунктата костного мозга $[1,2]$. Манифестация острых лейкозов может быть разнообразной, в клинической картине помимо анемического и геморрагического синдромов могут наблюдаться симптомы, обусловленные экстрамедуллярными поражениями. Лейкемическое поражение кожи с разной частотой встречается практически при всех видах лейкозов и может иметь любую локализацию. Экстрамедуллярные очаги могут предшествовать или развиваться одновременно с лейкозом, а также наблюдаться при прогрессировании или рецидиве заболевания [3]. Частота лейкемического поражения кожи при острых миелобластных лейкозах (ОМЛ) в дебюте заболевания не превышает 3\% [4], и в основном встречаются M4 и М5 варианты ОМЛ [1, 5, 6]. В 90\% случаев лейкемического поражения кожи выявляют другие экстрамедуллярные очаги, среди которых чаще всего наблюдается вовлечение менингеальных оболочек [7]. Патогенез экстрамедуллярного поражения различных органов и тканей связывают с наличием на опухолевых клетках хемокиновых рецепторов (хоуминг-рецепторов), определяющих тропность к тому или иному органу. При исследовании экспрессии хемокиновых рецепторов на бластных клетках периферической крови, костного мозга и кожи у детей с ОМЛ, протекающим с поражением кожи, было показано различие в экспрессии CCR5, CXCR4, CXCR7 и CXCR1. Вероятно, наличие на поверхности опухолевых клеток этих молекул адгезии объясняет их тропность к коже [8]. Лейкемическое поражение кожи может быть различным и проявляться папулами, везикулами, язвами, эритродермией [3, $9,10]$. В литературе описаны случаи лейкемического поражения кожи, напоминающие по типу кожных элементов псориаз, витилиго и себорейный дерматит [11]. Приблизительно в половине случаев (46\%) морфологического исследования очагов экстрамедуллярного лейкемического поражения первоначально устанавливается диагноз неходжкинской лимфомы, в ряде случаев - недифференцированного рака и меланомы [12]. В половине случаев лейкемического поражения кожи была выявлена трисомия или тетрасомия 8-й хромосомы [5]. У больных с лейкемическим поражением кожи уровень лактатдегидрогеназы и $\beta_{2}$-микроглобулина был достоверно выше, чем у больных без поражения кожи [5, 9]. Вероятность развития лейкемического поражения кожи не коррелирует с полом, возрастом больного, уровнем тромбоцитов, лейкоцитов, гемоглобина [5]. Многие авторы отмечают ассоциацию лейкемического поражения кожи с неблагоприятным прогнозом [5, 6].

В настоящей статье мы приводим собственное наблюдение лейкемического поражения кожи при ОМЛ.

\section{Клинический случай}

Женщина 78 лет обратилась в ФГБУ «Гематологический научный центр» Минздрава России с диагнозом направления лимфопролиферативное заболевание кожи. При поступлении пациентка предъявляла жалобы на появление уплотнений красно-синюшного цвета на всей поверхности кожных покровов и мучительный кожный зуд. Впервые кожные элементы появились за месяц до поступления, некоторые из них самостоятельно регрессировали с формированием участков гиперпигментации (рис. 1).

При осмотре выявлены множественные кожные элементы по типу тонких бляшек. При пальпации отмечено увеличение размеров шейных, шейно-надключичных, подмышечных лимфатических узлов до 40 мм. При исследовании периферической крови уровень гемоглобина был 122 г/л, тромбоцитов - $80 \cdot 10 \%$ л, лейкоцитов - 10,5 · 10\%, СОЭ 17 мм/ч. В лейкоцитарной формуле выявлен лимфоцитоз до 65\% (миелоциты $1 \%$, палочкоядерные нейтрофрилы 3\%, сегментоядерные нейтрофилы 28\%, моноциты 5\%). В биохимическом анализе крови отмечено повышение активности лактатдегидрогеназы - 575 E/л (норма 208-378 E/л), гаммаглутамилтранспептидазы - 136 Е/л (норма 5-32 Е/л), щелочной фоосфатазы - 212 Е/л (норма 30-120 Е/л), остальные показатели оставались в пределах нормы. При иммунохимическом исследовании белков сыворотки крови выявлено повышение уровня $\beta_{2}$-микроглобулина до 5,8 мг/л (норма < 2,4 мг/л), признаки воспалительной диспротеинемии. Ультразвуковое исследование брюшной полости выявило увеличение размеров селезенки до $156 \times 58$ мм (норма $110 \times 45$ мм), абдоминальных и забрюшинных лимсроузлов до 35 мм. На компьютерной томограмме органов грудной клетки обнаружено увеличение размеров внутригрудных лимфоузлов до 40 мм.

С диагностической целью пациентке была проведена биопсия измененного участка кожи, подмышечного лимфроузла и костного мозга. При гистологическом исследовании биоптата лимфатического узла было выявлено нарушение его гистоархитектоники за счет массивной диффрузной инфильтрации клетками крупных размеров. Капсула лимфатического узла и окружающая жировая клетчатка были резко утолщены, инсрильтрированы опухолевыми клетками. Крупные клетки содержали большое светлое ядро неправильной фрормы с несколькими мелкими ядрышками (рис. 2). В биоптате кожи выявлена массивная инфильтрация аналогичными клетками всех слоев дермы без признаков эпидермотропизма (рис. 3). Морфологическая картина, выявленная в биоптатах лимфоузла и кожи, не противоречила наблюдаемой при лимфопролиферативных заболеваниях, но не позволяла уточнить вид неходжкинской лимфомы. Для уточнения генеза поражения лимфатических узлов и кожи проведено иммуногистохимическое исследование с расширенной панелью моноклональных антител. Опухолевые 


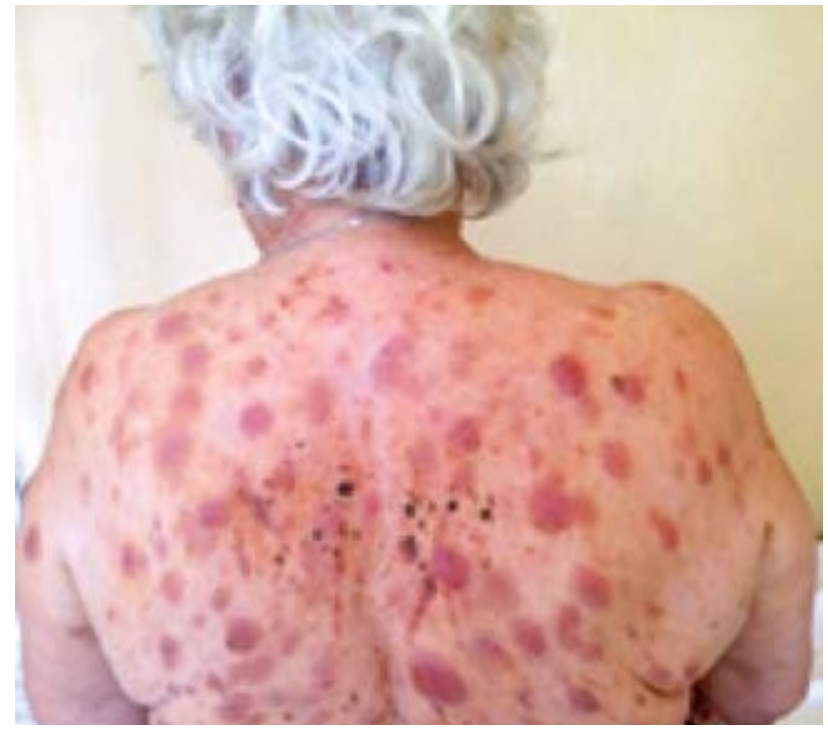

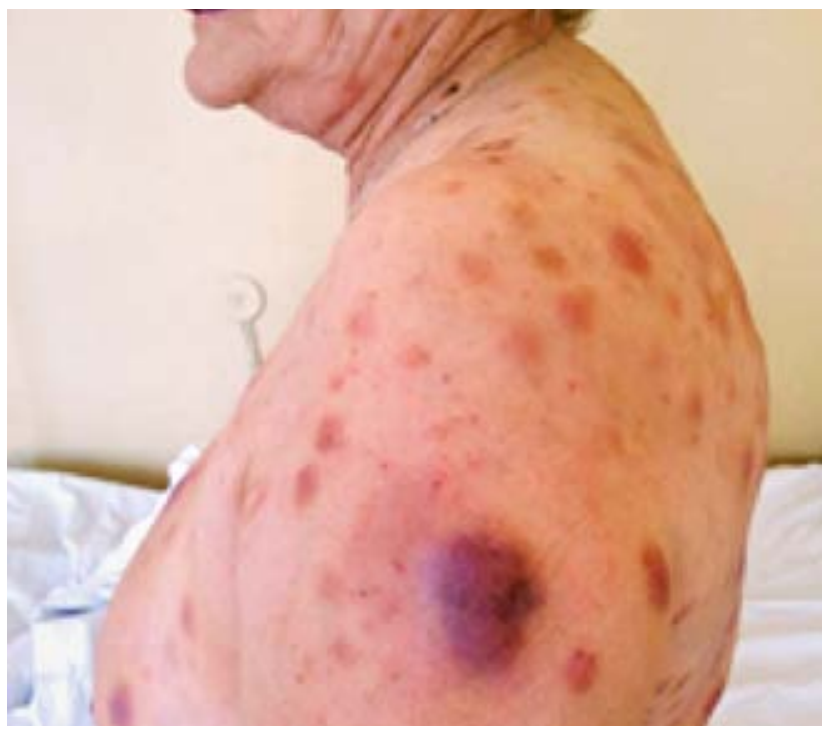

$\sigma$

Рис. 1. Внешний вид кожных покровов у больной

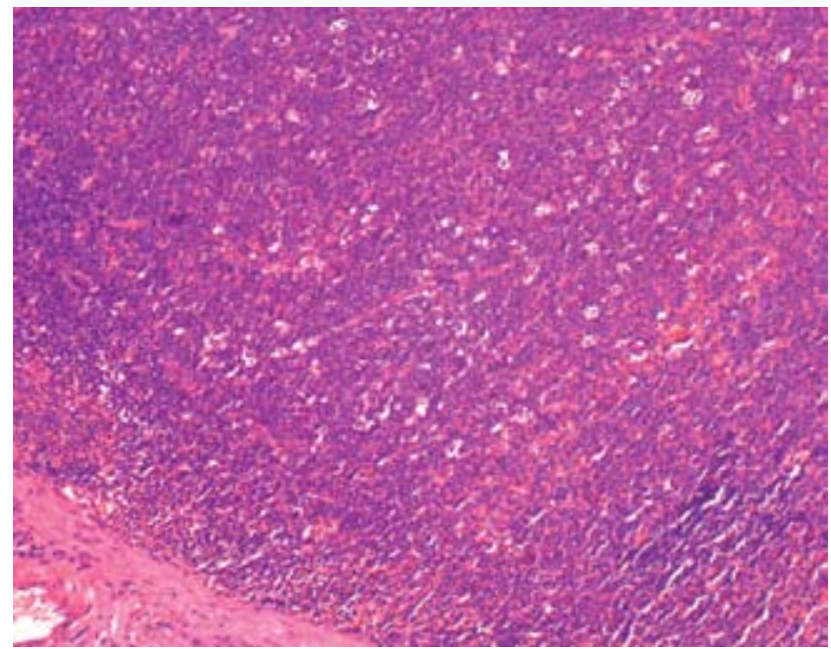

a

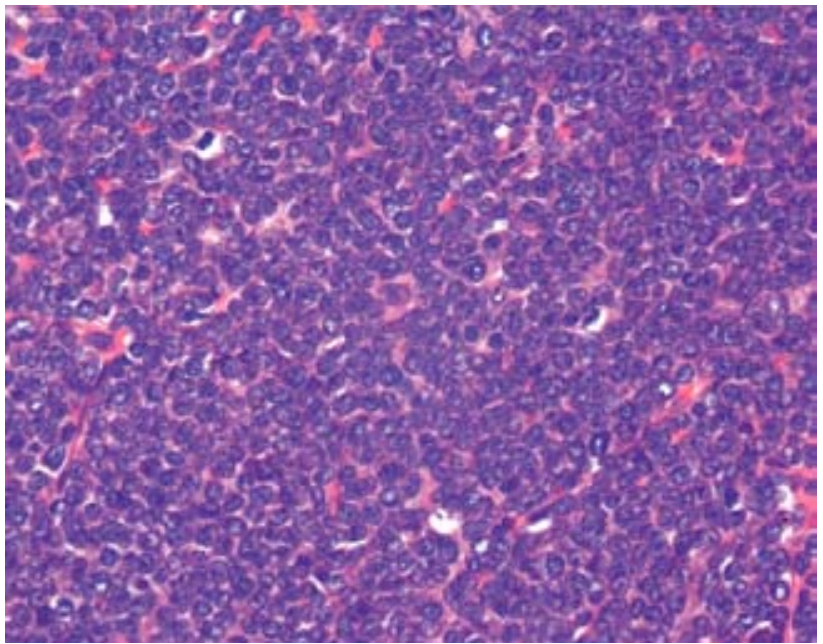

б

Рис. 2. Гистологическое исследование биоптата лимфоузла. Нарушение гистоархитектоники лимфоузла за счет массивной дифффузной инсильттрации клетками крупных размеров. Клетки крупных размеров содержат большое светлое ядро неправильной формы с несколькими мелкими ядрышками. Здесь и на рис. 3 окраска эозином и гематоксилином: $a-\times 100 ; \sigma-\times 400$

клетки биоптата лимфоузла и кожи экспрессировали CD7, CD45, CD14, CD33 и CD68, были негативны при исследовании маркеров CD20, PAX5, CD3, BCL2, BCL6, CD10, MUM1, CD5, CD23, миелопероксидазы, TdT, CD34. Выявленная иммуногистохимическая картина соответствовала лейкемическому поражению кожи и лимфоузла при монобластном лейкозе.
При морфологическом исследовании костного мозга были выявлены клетки больших размеров с умеренно высоким ядерно-цитоплазматическим соотношением, крупным, преимущественно округлым ядром с нежной сетчатой структурой хроматина, 1-2 нуклеолами и умеренно базофильной цитоплазмой. Отдельные бластные клетки содержали в цитоплазме нежную азу- 


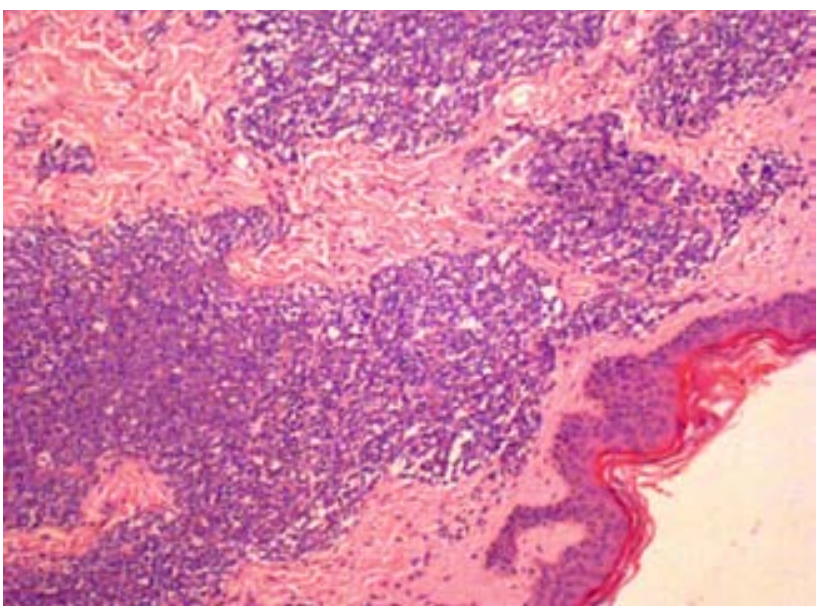

a

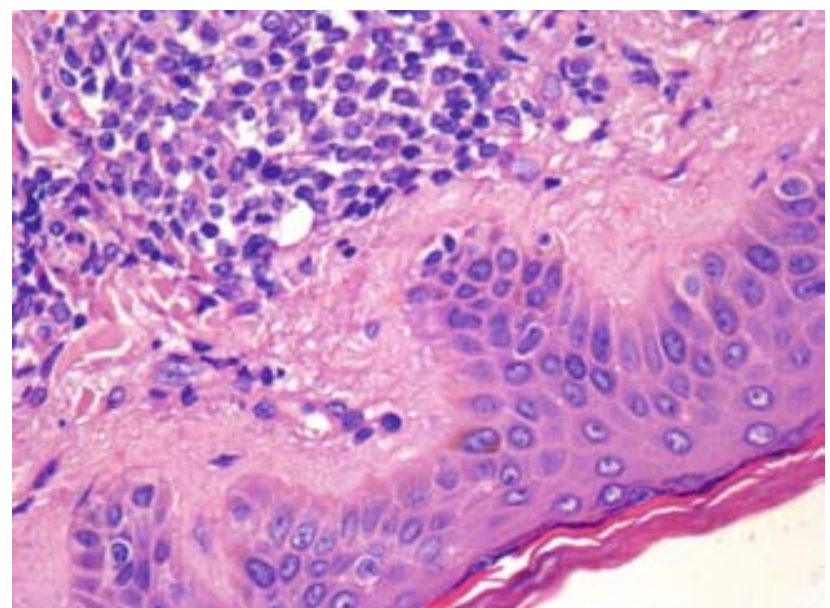

б

Рис. 3. Гистологическое исследование биоптата кожи. Массивная инфильтрация всех слоев дермы аналогичными клетками крупных размеров без признаков эпидермотропизма

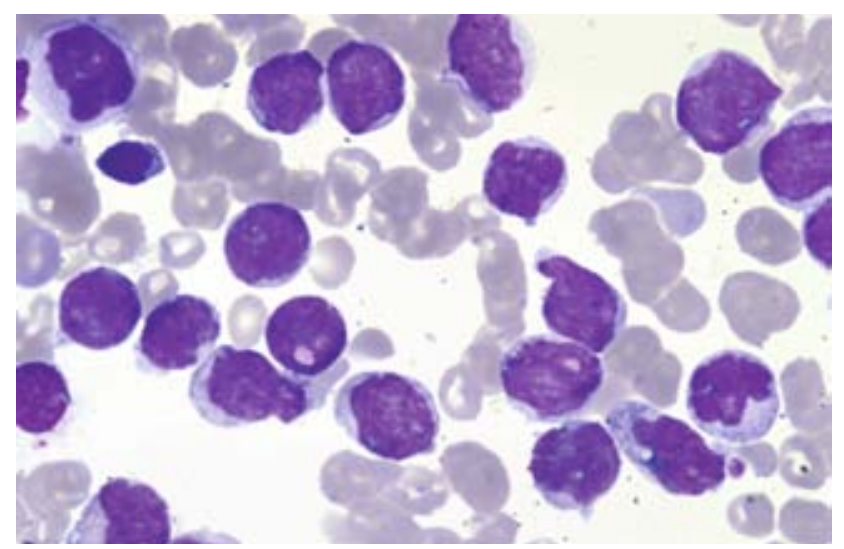

Рис. 4. Цитологическое исследование пунктата костного мозга. Окраска по Романовскому Гимзе. $\times 1000$

рофильную зернистость и имели псевдоподии (рис. 4). Опухолевая популяция, составившая 79\% от всех ядросодержащих клеток костного мозга, характеризовалась отрицательной цитохимической реакцией на миелопероксидазу и высокой реакцией на неспецифическую эстеразу, полностью ингибируемую фрторидом натрия. Иммунофенотипическая характеристика клеток костного мозга была подобна выявленной в лимфоузле и коже. При стандартном цитогенетическом исследовании костного мозга хромосомные аберрации не были обнаружены, наблюдался нормальный кариотип 46 XX [20].

Таким образом, на основании проведенных морфологических и иммунофенотипических исследований костного мозга, лимфоузла и кожи был верифицирован ОМЛ, протекающий с поражением кожи и лимфоузлов.
При динамическом мониторинге показателей гемограммы через неделю выявлено снижение уровня гемоглобина до 106 г/л и тромбоцитов до 69 · 10\%/л. Количество лейкоцитов увеличилось в 2 раза $(20,7$. 10\%) за счет появления бластных клеток (50\%) в периферической крови. После первого курса противоопухолевой терапии наступила смерть от инфекционных осложнений.

\section{Обсуждение}

В нашу клинику поступила пожилая пациентка с быстропрогрессирующим поражением кожных покровов и мучительным кожным зудом. Именно эти симптомы послужили поводом для обращения к врачу и оказались первыми проявлениями ОМЛ. Поражение кожи по типу тонких бляшек может как наблюдаться при метастатическом вовлечении кожи при гемобластозах, так и быть проявлением первичных лимфопролиферативных заболеваний кожи [1]. Стремительное распространение кожных элементов, вовлечение периферических лимфоузлов и мучительный кожный зуд свидетельствовали об агрессивности клинического течения заболевания. Морфологическое исследование биоптатов кожи и лимсратического узла не противоречило лимфомному поражению, но и не позволило верифицировать вид неходжкинской лимфомы. Выполненное иммуногистохимическое исследование с расширенной панелью моноклональных антител биоптатов кожи и лимфрозла позволило определить линейную принадлежность опухолевых клеток, верифицировать лейкемическое поражение кожи и лимфоузлов. Показаниями к исследованию костного мозга, выявившему развернутую картину острого лейкоза, явились тромбоцитопения и лимфоцитоз в периферической крови. Отсутствие комплексного клинического обследования в подобных случаях приво- 
дит к диагностическим ошибкам, поздней верификации истинного диагноза и существенно ухудшает прогноз.

\section{Заключение}

В статье представлен нестандартный алгоритм верифрикации лейкемии, протекающей с экстрамедул- лярными очагами поражения. Морфологическое, иммуногистохимическое исследования биоптатов кожи, лимфоузла и костного мозга позволили установить линейную принадлежность опухолевых клеток и своевременно верифицировать диагноз острого монобластного лейкоза.
1. Swerdlow S. H., Campo E., Harris N. L., Jaffe E. S., Pileri S. A., Stein H., Thiele J., Vardiman J.W. WHO classification of tumor of haematopoietic and lymphoid tissues. Lyon: IARC; 2008.

2. Savchenko V. G., Parovichnikova E. N., Afanasyev B. V., Gritsayev S. V., Semochkin S. V., Bondarenko S. N., Troitskaya V. V., Sokolov A. N., Kuzmina L. A., Klyasova G.A., Gaponova T. V., Baranova O.Yu., Lapin V.A., Konstantinova T. S., Samoylova O. S., Kaporskaya T. S., Shatokhin S. V. Natsionalnyye klinicheskiye rekomendatsii po diagnostike i lecheniyu ostrykh miyeloidnykh leykozov vzroslykh. Gematologiya i transfuziologiya. 2014. T. 59. N S2. S. 2-29. [Савченко В.Г., Паровичникова Е.Н., Афранасьев Б.В., Грицаев С. В., Семочкин С.В., Бондаренко С.Н., Троицкая В.В., Соколов А.Н., Кузьмина Л. А., Клясова Г. А., Гапонова Т. В., Баранова О.Ю., Лапин В.А., Константинова Т. С., Самойлова О.С., Капорская Т. С., Шатохин С.В. Национальные клинические рекомендации по диагностике и лечению острых миелоидных лейкозов взрослых. Гематология и трансфузиология. 2014. Т. 59. N S2. C. 2-29]

3. Cho-Vega J.H., Medeiros L. J., Prieto V. G., Vega F. Leukemia cutis Am J Clin Pathol. 2008 Jan;129(1):130-42. DOI: 10.1309/WYACYWF6NGM3WBRT.

\section{Литература}

4. Chang H., Brandwein J., Yi Q. L., Chun K., Patterson B., Brien B. Extramedullary infiltrates of AML areassociated with CD56 expression, 11 q23 abnormalites and inferior clinical outcome. Leuk Res. 2004 Oct; 28(10):1007-11. DOl: 10.1016/j.leukres.2004.01.006.

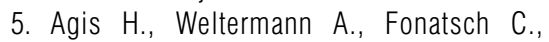
Haas 0., Mitterbauer G., Müllauer L., Schreiber S., Schwarzinger I., Juretzka W., Valent P., Jäger U., Lechner K., Geissler K. A comparative study on demographic, histological and cytogenetic findings and prognosis in acute myeloid leukemia with and without leukemia cutis. Ann Hematol 2002 Feb; 81(2): 90- 5. DOl: $10.1007 / \mathrm{s} 00277-001-0412-9$.

6. Rukavitsyn A. 0., Lamotkin I. A., Antipova A. S. Kharakteristika spetsificheskikh porazheniy kozhi pri ostrykh leykozakh. Gematologiya. Transfuziologiya. Vostochnaya Evropa. № 2 (02). 2015. S. 135-141. [Рукавицын А. О., Ламоткин И.А., Антипова А. С. Характеристика специфических поражений кожи при острых лейкозах. Гематология. Транссузиология. Восточная Европа. №2 (02). 2015. C. 135-141.]

7. Long J. C., Mihm M. C. Multiple granulocytic tumors of the skin: report of six cases of myelogenous leukemia with initial manifestations in the skin. Cancer 1977 May; 39 (5): 2004-16.
8. Faaij C.M., Willemze A.J., Revesz T., et al. Chemokine/chemokine receptor interactions in extramedullary leukaemia of the skin in childhood AML: Differential roles for CCR2, CCR5, CXCR4 and CXCR7. Pediatr Blood Cancer 2010:55; 344-348. doi: 10.1002/pbc.22500.

9. Sharma S. K, Gupta S., Seth T., Mishra P., Mahapatra M., Singh M.K., Gupta S. Leukemia Cutis: An Unusual Presentation Indian J Hematol Blood Transfus. Sep 2012; 28 (3): 175-177. doi: 10.1007/s12288-011-0113-z.

10. Martínez-Escanamé M., Zuriel D., Tee S.I., Fried I., Massone C., Cerroni L. Cutaneous infiltrates of acute myelogenous leukemia simulating inflammatory dermatoses. Am J Dermatopathol 2013 Jun; 35 (4): 419—24. doi: 10.1097/DAD.0b013e31826ffe6f.

11. Kaddu S., Zenahlik P., Beham-Schmid C., Kerl H., Cerroni L. Specific cutaneous infiltrates in patients with myelogenous leukemia: A clinicopathologic study of 26 patients with assessment of diagnostic criteria. J Am Acad Dermatol 1999 Jun; 40 (6 Pt 1): 966-78.

12. Byrd J. C., Weiss R. B., Arthur D. C., Lawrence D., Baer M.R., Davey F., Trikha E. S., Carroll A.J., Tantravahi R., Qumsiyeh M., Patil S. R., Moore J. O., Mayer R.J., Schiffer C.A., Bloomfield C.D. Extramedullary leukemia adversely affects hematologic complete remission rate and overall survival in patients with t(8;21)(q22;q22): results from Cancer and Leukemia Group B 8461. J Clin Oncol 1997 Feb; 15 (2): 466—75.

об авторах:

Н.Г. Чернова — к.м.н., научный сотрудник научно-клинического отделения химиотерапии лимфом ФГБУ ГНЦ Минздрава России, Москва

М. Н. Синицына — научный сотрудник паталогоанатомического отделения ФГБУ ГНЦ Минздрава России, Москва

В.Н. Двирнык — к.м.Н., зав. централизованной клинико-диагностической лабораторией ФГБУ ГНЦ Минздрава России, Москва

А. М. Ковригина — д.б.н., зав. паталогоанатомическим отделением ФГБУ ГНЦ Минздрава России, Москва

Е. Е. Звонков - д.м.Н., зав. научно-клиническим отделением химиотерапии лимсом ФГБУ ГНЦ Минздрава России, Москва

Е. Н. Паровичникова - д.м.н., руководитель научно-клинического отделения высокодозной химиотерапии и трансплантации костного мозга ФГБУ ГНЦ Минздрава России, Москва

\section{Конфликт интересов}

Авторы заявляют об отсутствии потенциального консрликта интересов, требующего раскрытия в данной статье 